


\section{La noción del marco referencial a través de los paratextos en El diario inédito del filósofo vienés Ludwig Wittgenstein, de Fredy Yezzed}

\section{The notion of referential framework through the paratexts in El diario inédito del filósofo vienés Ludwig Wittgenstein, by Fredy Yezzed}

Manuel Ernesto Parra Aguilar Universidad Autónoma del Estado de Morelos, México

Resumen: En este trabajo se expone cómo algunos elementos paratextuales que rodean a un texto pueden influir en la interpretación del mismo. Se verá El diario inédito del filósofo vienés Ludwig Wittgenstein (2016), de Fredy Yezzed (Bogotá, 1979), y se analizarán el título, los epígrafes y la cuarta de forros, para ver cómo es que éstos intervienen en el lector antes de su encuentro con la obra, la cual se encuentra en diálogo constante con otras obras de Wittgenstein y otros autores, participando así en una atmósfera transtextual.

Palabras clave: Wittgenstein, transtextualidad, paratexto, posmodernidad, poema en prosa. 
Abstract: In this article, we will expose how some paratextual elements that surround a text can influence the interpretation of it. We will approach to El diario inédito del filosofo vienés Ludwig Wittgenstein (2016), by Fredy Yezzed (Bogotá, 1979), exploring the title, the epigraphs and the inside back cover, to see how is it that these elements intervene previously in the reader and his encounter with Yezzed work, which have a constant dialogue with other works by Wittgenstein and many other authors, thus participating in a transtextual atmosphere.

Keywords: Wittgenstein, Transtextuality, Paratext, Postmodernity, Prose poem.

Recibido: 10 de julio de 2018

Aceptado: 10 de octubre de 2018

\section{Presentación}

To primero con lo que se encuentra el lector de una obra litera—ria es el título, por lo tanto la lectura de ese elemento textual lo prepara para su interpretación. Esto tiene una connotación especial cuando el título hace referencia a un género literario y a un nombre histórico, como sucede con El diario inédito del filósofo vienés (2016), escrito por Fredy Yezzed.

El diario inédito... es un libro publicado en primera instancia en el año 2012 por Ediciones del Dock, Buenos Aires, con una serie de modificaciones en la segunda edición de 2016 por la misma editorial, ${ }^{1}$ modificaciones significativas con respecto a la primera, ya que se suprimen algunas partes y se resaltan otras. Según se lee

${ }^{1}$ Incluso con otros cambios y añadidos en la tercera edición (electrónica) de $E l$ diario inédito... (Fundarte, Caracas, 2016), aun cuando en la segunda edición se puede leer en la ficha técnica: "Tómese la $2^{a}$ edición de El diario inédito del filósofo vienés Ludwig Wittgenstein como la última versión y la definitiva”. Para este estudio se tomará la edición de Ediciones del Dock de 2016, ya que los cambios de la edición venezolana no modifican el sentido de la obra. 
en la edición impresa, este libro obtuvo Mención de Honor en el Premio Nacional de Literatura-Poesía 2007, certamen convocado por el Ministerio de Cultura de Colombia; sin embargo, no se publicó sino hasta el año 2012 gracias al Apoyo a la edición de un libro de autor de la Red Nacional de Talleres de Escritura Creativa (RENATA) del ministerio antes señalado, beneficio obtenido en el año 2010.

El diario inédito... es un conjunto de poemas en prosa, compuesto de siete capítulos (así los denomina su autor en el prólogo a la obra) que comienzan con una numeración arábiga. Los temas predominantes, en el orden de aparición, son los siguientes: límites del pensamiento poético, estructura lógica de los juegos poéticos, situación amorosa, reflexión mística, aspectos biográficos y autobiográficos, reflexión sobre la situación del ser del hombre, y lo decible y lo indecible. El libro se apoya en la fragmentación que se encuentra en el género diarístico y en la transtextualidad con entrevistas al autor, diarios, hibridación de géneros literarios, en donde se halla un diálogo constante con obras propias y ajenas al filósofo vienés.

Dentro de los estudios literarios, la Estética de la Recepción hace uso del concepto de horizonte de expectativas, es decir aquellas previsiones variables que el lector espera encontrar dentro de la obra a la que se enfrenta, en la cual intervienen aspectos sociales y culturales de quien lee, y en donde tiene parte importante el título de la misma (Iser: 2015). Sobre esta idea, Pere Ballart menciona que el percibir un objeto dentro de límites definidos, que lo recortan y apartan, hace que el espectador le preste una atención preferente, dándole un valor distinto al que se le otorgaría de modo rutinario (2005: 28). Así, la noción de marco separa y diferencia ese objeto de otros tantos, también implica darle sentido a lo que se encuentra dentro del marco. Ballart resalta: 
El marco desempeña la función de umbral y de muralla, es a la vez vestíbulo y aduana. Y por cuanto su influencia sobre el receptor condiciona directamente la actitud que éste adopte frente a la obra, quizá no esté de más sugerir que se trata de un concepto cuyas raíces kantianas lo aproximan bastante al de "horizonte" (2005: 39).

Así, la noción de marco delimita e incluso puede determinar el sentido de una obra, sentido en el que participan los paratextos, es decir aquellos textos que tienen relación directa con la obra, como lo son las solapas, la cuarta de forros, prólogos y epígrafes, entre otros. Dentro de la mención paratextual se encuentra el título, en donde, "cuando no hay ninguna mención [de pertenencia taxonómica, como poemas, novelas, biografías, etc.], puede deberse al rechazo de subrayar una evidencia o, al contrario, para recusar o eludir cualquier clasificación" (Genette, 1989: 13). En ello interviene el lector con su horizonte de expectativas con unos marcos propuestos en la obra que hacen que ese horizonte se amplíe o incluso se cierre.

\section{El título}

Pere Ballart señala que el título de una obra literaria puede funcionar como un marco en donde el lector ingresa aceptando el juego propuesto por el autor. En el caso particular de El diario inédito... sería sólo un diario más de Wittgenstein de los que se conocen hasta hoy, como los titulados Diarios secretos, ligados a la intimidad de su autor y publicados a mediados de los años ochentas del siglo pasado (Pérez, 2016: 72).

Al seguir la idea de la referencialidad del título, Ángel Luis Luján menciona que su presencia es un indicio de la actitud del poeta, a la vez que en él se anuncian determinadas técnicas empleadas en su interior (2000: 30). Incluso se puede decir que "el título tiene 
una función fática, de contacto: advierte del comienzo del mensaje y dispone los ánimos de los lectores” (2000: 31). Luján resalta que el mismo título puede funcionar de modo referencial, orientando al lector ya sea con nombres propios o comunes o haciendo alusión a un subgénero (2000: 31-32), en este caso un supuesto diario literario. Por otro lado, siguiendo a Genette, en El diario inédito... se parte de la hipertextualidad, ${ }^{2}$ puesto que, a partir de la relación del título con aquellos diarios íntimos de Wittgenstein, el libro de Yezzed se pone en contacto directo con ellos ofreciendo al lector un tipo de diario literario "inédito". Así, el título El diario inédito... condiciona al lector de cierta manera: se trata de un tipo de diario que, al igual que los diarios íntimos, no se espera que revele algo de las teorías wittgensteanas (que al cabo los diarios del pensador tampoco lo hacen), sino que aporte a la comprensión del hombre detrás de esas teorías.

El marco referencial del título propuesto en El diario inédito... se encuentra relacionado, primero, con los hipertextos diarísticos $y$, en segunda instancia, con hechos y obras reconocibles, como sucede con Wittgenstein y sus teorías con respecto al uso del lenguaje y con los diarios de Wittgenstein que, si bien no se pensaron en su momento para la publicación, los albaceas de Wittgenstein, G. H. von Wright, E. Anscombe y R. Rhees, han dado a la imprenta y se conocen hoy (Pérez, 2016: 72).

Hans Rudolf Picard menciona tres tipos de diarios: el diario íntimo, el diario ficcional o literario y el diario con miras a su publicación (1981: 117-119).

El diario íntimo es aquel que en ningún momento se abre para que cualquier otro lector ajeno al propio autor pueda leerlo, por lo

${ }^{2}$ Genette menciona que la hipertextualidad es cuando un primer texto provoca otro, el cual le llega al lector; es decir, de alguna manera, es el que inspira al autor a crear un nuevo texto donde pueden incluir la parodia, la transposición, la imitación. 
tanto se opone totalmente al diario con miras a su publicación, el cual espera que su monólogo sea escuchado por cualquier público. Ejemplos de este segundo tipo de textos son el Diario de un poeta recién casado (1916) de Juan Ramón Jiménez, el Diario de André Gide (escrito entre 1887 y 1948, y publicado completo por primera vez en 1996) y El peso del mundo (1977) e Historia del lápiz. Vida y escritura (1991), de Peter Handke.

El diario ficcional, por su parte, aprovecha los recursos literarios para crear un personaje ficticio y emitir un discurso, lo cual ofrece dos ventajas: "primero, el hecho de que el diario literario depare la posibilidad de penetrar en el proceso de la escritura, y, segundo, el que evite las constricciones de la estructuración de la obra y el presunto carácter descomprometido de la ficción" (Picard, 1981: 118). Ejemplos de este tipo de diarios son El diario de José Toledo (1964), de Miguel Barbachano Ponce, y Brenda Berenice o el diario de una loca (1985), de Luis Montaño, entre otros.

Por otro lado, Manuel Hierro ofrece tres distinciones de diario: el diario, el diario íntimo y el diario externo. El primero es un recuento indistinto de la escritura cotidiana; el segundo no está pensado para su publicación durante la vida del autor (sin embargo Hierro no señala la publicación del diario después de la muerte de su autor) aunque facilita el conocimiento de la vida de éste; el tercero, por su lado, confiere más relevancia a los acontecimientos que al sujeto, por lo que se acerca a la crónica (Hierro, 1999: 114).

Dentro del horizonte de expectativas condicionadas por el marco referencial del título, en El diario inédito... el lector se encuentra con una obra anunciada como un supuesto diario que ayuda a comprender al pensador, más allá de la imagen tradicional analítica que se puede tener de él. Y es que a las diferencias que existen entre la imagen oficial de Wittgenstein por parte de sus albaceas y la otra imagen como persona común, se añade el hecho de que aquellos diarios del Wittgenstein - un tanto distanciado de la lógica y las 
matemáticas- no se publicaron sino hasta 1985 en Barcelona, en una edición bilingüe alemán-español, bajo el título de Diarios secretos (Pérez, 2016: 74). Con esta publicación se añade una mayor comprensión del pensamiento (no de las teorías) del filósofo vienés y de la cual se pueden derivar otras manifestaciones artísticas, como los libros de poemas La sombrilla de Wittgenstein (2007), de Marcelo Daniel Díaz, Guía para perderse en la ciudad (2010), de Víctor López Zumelzu, o El diario inédito..., de Fredy Yezzed, e incluso con Wittgestein (1993), película de Derek Jarman.

En el horizonte de expectativas que tiene el lector de El diario inédito..., el marco referencial del título interviene en gran medida; se menciona a un diario con un nombre histórico y se prepara al lector para la interpretación de la misma obra. Sin embargo, desde el título este libro cuestiona la tradición del diario, el cual debería estar firmado por un yo más o menos reconocible dentro del mismo diario. Y es que con propuestas distintas a las tradicionales, un diario literario contemporáneo cuestiona los convencionalismos de este género, poniendo en debate la misma idea de pertenencia taxonómica.

\section{Prólogo}

Gerard Genette define el término "transtextualidad" como "la trascendencia textual del texto" (1989: 9). Es oportuno traer el término a colación para desentrañar las relaciones de una obra como El diario inédito... a partir del prólogo, el cual es un paratexto, ${ }^{3}$ según Genette (1989: 11), así como de otros elementos paratextuales como los epígrafes y la cuarta de forros, que se verán en los próximos apartados.

${ }^{3}$ Genette menciona como paratextos aquellos textos que tienen relación directa con la obra e influyen en gran medida en la apreciación de la misma, como el título, subtítulo, intertítulos, prefacios, epílogos, advertencias, prólogos, etc. (1989: 11) 
En el prólogo de El diario inédito..., dividido en tres párrafos, se menciona primero cómo es que Wittgenstein participó como voluntario en la Primera Guerra Mundial, fue prisionero y se propuso escribir el Tractatus logico-philosophicus:

En 1921 aparece la primera edición en alemán del Tractatus logico-philosophicus del filósofo vienés Ludwig Wittgenstein (18891953), un trabajo meditado en el transcurso de la Primera Guerra Mundial, en la cual el intelectual de raíces judías decide participar como voluntario, a pesar de estar impedido por una hernia y sufrir trastornos depresivos que colindaban con el suicidio (2016: 9).

En el segundo párrafo se señala que la obra es "expresión artística" y que algunos amigos lectores le han adjudicado al libro cierto toque filosófico:

Con la poca humildad que conceden los prólogos propios o ajenos, sostengo, si bien con incertidumbre, desde mi valoración como autor, que El diario inédito... está inserto dentro del género o la "forma" que llamamos poesía. No obstante, poesía o no poesía, esa no es la cuestión; lo importante y vital es que es expresión artística (2016: 9). ${ }^{4}$

En el tercer párrafo se menciona que la obra se estructura a partir del Tractatus, tomando el sistema decimal de aquel libro de Wittgenstein y los siete apartados (capítulos, los denomina Yezzed) de los que se compone. Así mismo, el autor menciona que se trata de la "asimilación de la obra de Wittgenstein" (2016: 10).

Siguiendo a Genette, Juana Marinkovich resalta el hecho de que la propia transtextualidad puede incluir la citación o incluso el plagio, lo mismo que la alusión a ese otro texto (1999: 732). Dentro de ese "plagio" que señala Marinkovich cabría preguntarse

${ }^{4}$ Los resaltados son del autor. 
hasta dónde o qué tanto es que puede ser permitido en las obras literarias. En el prólogo a El diario inédito... Yezzed resalta la "obvia razón de inventar mi propio Wittgenstein y sumergirme en la veta expresiva que subyace en sus trabajos" (2016: 9-10). En cuanto a la reutilización de la obra de Wittgenstein, Yezzed señala:

La obra que presento toma el sistema decimal a partir del cual está organizado el Tractatus, tabla o línea de una estructura del pensamiento, que en algunos casos es dislocada y caótica como el divagar de la imaginación y las preocupaciones, pero que busca una relación íntima y, en el fondo, una poesía que revele -como creo que intenta todo artista- la tragedia del hombre actual (2016: 10).

Otro aspecto que resalta este prólogo es que sólo se menciona a Wittgenstein y la organización del Tractatus pero no se habla en sí de la forma utilizada, el diario; un diario que se apropia de distintas manifestaciones artísticas, un texto que no sólo se mantiene en comunicación constante con otros textos sino que incluso se apropia de ellos en una especie de híbrido entre la paratextualidad y la hipertextualidad. Por otro lado, esta hibridez también resulta de la fusión de dos o más géneros literarios, como el supuesto diario y el género en el que se alude del contenido del propio diario: el poema.

\section{Epígrafes}

Otros paratextos que funcionan como marcos referenciales para la interpretación de El diario inédito... son los epígrafes:

Los limites de nuestro lenguaje

significan los limites de nuestro mundo. 
El escepticismo de los poetas puede servir de estímulo a los filósofos. Los poetas, en cambio, pueden aprender de los filósofos el arte de las grandes metáforas, de esas imágenes útiles por su valor didáctico e inmortales por su valor poético.

Antonio Machado

[Wittgenstein] tiene el orgullo de Lucifer.

BERTRAND RusSELL

Estos tres ${ }^{5}$ epígrafes refuerzan el contenido explícito del libro: Wittgenstein y sus teorías con respecto al uso del lenguaje, además de la relación existente entre filosofía y poesía, pues ambas buscan una verdad, en este caso la verdad interior de un Wittgenstein inventado, según su autor, en un diario que hasta entonces se consideraba inédito. En este sentido es relevante recordar que Wittgenstein sólo se planteó la publicación de dos libros: el Tractatus y las Investigaciones filosóficas, las cuales se publicaron póstumamente. ${ }^{6}$

\section{Cuarta de forros}

Por otro lado, sobre la cuarta de forros (otro paratexto, siguiendo a Genette) -publicada en las ediciones 2012 y 2016 y firmada por los poetas Gonzalo Rojas, Marco Antonio Campos y Juan Manuel Roca-, Omar Ardila menciona:

${ }^{5}$ En la edición venezolana de 2016 hay un cuarto epígrafe: "Mucho de su vida permanecerá desconocido/ para siempre a sus amigos más íntimos" de Fania Pascal.

${ }^{6}$ Esta segunda obra Wittgenstein refuta el Tractatus, por lo que algunos estudiosos de la obra del filósofo vienés señalan que existen dos periodos de Wittgenstein. 
[El diario inédito...] es un libro que pudo haber merecido el premio de poesía del Ministerio de Cultura de Colombia en el 2007, cuando fue presentado a concurso; sin embargo, apenas recibió una mención honorífica, justificada en un comentario que deja muchas dudas sobre la cabal comprensión y aceptación de otras formas de relacionarse con la poesía, por parte de los jurados (2014).

El comentario que menciona Ardila es el que se encuentra en la cuarta de forros del libro, que es la siguiente:

Libro de agudos aforismos. Bello e inquietante. O, mejor, bello en su convulsa manera de reflejar el mundo. Desde la fragmentación, tan cara a Nietzche, el autor del libro crea una especia de poliedro en el que se pregunta sobre el pensar, sobre la escritura, sobre el lenguaje, el amor y la muerte. Es un libro deslumbrante y lúcido. De una cerrada unidad en estilo y desarrollo temático. Muy interesante su seguimiento de los fragmentos wittgenstianos. Una suerte de aforismos y pensamientos que se vuelven intensa poesía. Casi todos los fragmentos deslumbran u obligan a la reflexión.

Este paratexto prepara al lector sobre el contenido: "libro de agudos aforismos" se menciona, y cuando se leen los fragmentos de la obra éstos se acercan justamente a los aforismos, pero también a las sentencias, declaraciones, greguerías, entre otros; por ejemplo: "1.1 La poesía es un jardín: un jardín que habla de otros jardines" (Yezzed: 2016: 15), o bien en: "6.36 La muerte no es un acontecimiento de la vida. No se vive la muerte” (2016: 71). En ambas citas, se puede interpretar la filiación transtextual del libro con otros más; decir, un libro que habla de otros libros, incluso con el Wittgenstein del Tractatus en la segunda cita: "6.4311 La muerte no es ningún acontecimiento de la vida. No se vive la muerte" (Wittgenstein, 2016: 143). 
El diario inédito de Wittgenstein también se apropia de entrevistas a Yezzed; en una entrevista de Jorge Consuegra a Yezzed, éste último manifiesta: "Recuerdo las palabras de un muerto muy querido para mí, el poeta Henry Luque Muñoz: 'Escribe no para que te lean, sino para que no te olviden'. Pero eso cuesta mucho trabajo y hay que esperar a que otros te escriban" (2011). Eco que se encuentra en El diario inédito...: "2.12 No escribas para que te lean; escribe para que no te olviden" (Yezzed, 2016: 26).

Pero también en entrevistas ajenas al autor, como la entrevista que en 1963 Grazia Livi le hizo a Ezra Pound, donde el poeta estadounidense, a pregunta expresa, señala: "El mundo contemporáneo no existe. No existe nada que no esté en relación con el pasado y con el futuro. El mundo actual es una fusión, un arco en el tiempo. Pero se lo repito, yo ya no sé nada. He llegado demasiado tarde a la incertidumbre total..." mientras que en la proposición 6.21 de El diario inédito... se menciona, con cursivas: Llegué demasiado tarde / a la total incertidumbre. / Sólo tengo conciencia de la duda (2016: 69).

\section{Participaciones posmodernas de El diario inédito...}

Este tipo de obras en las que ciertas características paratextuales e incluso los marcos referenciales cumplen un papel relevante y de reflexión aparecen tanto en la modernidad como en la llamada posmodernidad. Ihab Hassan menciona que la posmodernidad es algo inasible: no se sabe exactamente dónde comienza y dónde termina (si es que terminó) aunque, eso sí, existen ciertas características que se pueden encontrar en la literatura posmoderna con otro tipo de literatura (2007: 20), como la literatura moderna. Hassan ofrece una lista paratáctica de características posmodernas (aunque el teórico reconoce que no son propiamente una definición en sí del posmodernismo, sí son un intento por contenerlo) en la que 
incluye la fragmentación, los textes scriptibles de Roland Barthes y la muerte de Dios, del autor, además de la descanonización, es decir el cuestionamiento de todas aquellas convenciones de autoridad que se asumen, y sobre todo la hibridación de los géneros, en la cual interviene una intemporalidad, una nueva relación entre elementos históricos, sin supresión alguna del pasado en favor del presente (2007: 25).

En este mismo punto, Erika Fischer-Lichte menciona que ciertas características de la posmodernidad se pueden encontrar en la modernidad, como la indeterminación, la transtextualidad, la hibridación, la apertura de las formas, entre otras. Además FischerLichte resalta que en el nivel semántico de los textos se mencionan ante todo, de manera particularmente frecuente, la representación de mundos posibles, la redefinición de la relación entre espacio y tiempo (2007, 155); esto además de que en el nivel sintáctico de las obras una característica posmoderna puede ser la incoherencia.

Lo anterior es relevante para la posible interpretación que se le pueda dar a una obra como El diario inédito... a partir de los marcos de referencia, título, prólogo, cuarta de forros, epígrafes e incluso la información que puedan incluir las solapas; pues el lector puede ser cómplice de esos marcos o bien la misma obra puede abrirse para que el lector desentrañe el argumento de la misma, sobre todo cuando se leen fragmentos como: "5.113 Otra vez no quisiera nada. Ni una madre quisiera otra vez" (Yezzed, 2016: 47). Ya que las dos oraciones pertenecen a Antonio Porchia (18861968) y se encuentran en el libro Voces publicado a principio de los ańos cuarenta del siglo pasado, en Argentina. O por ejemplo en: “5.1412 'Vine a Comala porque me dijeron que acá vivía mi padre, un tal Pedro Páramo', dijo Juan Rulfo unos instantes después de haber muerto (Yezzed, 2016: 51). Fragmentos que se encuentran en forma de verso en la revista electrónica Círculo de poesía bajo el título de "Mariposas negras para Juan Rulfo": 
"Vine a Comala porque me dijeron que acá vivía mi padre, un tal Pedro Páramo"

dijo Juan Rulfo

un instante después de haber muerto

\section{Conclusiones}

El título es uno de los primeros encuentros del lector con una obra literaria; sirve como un marco referencial del posible contenido del libro, ya que incluso puede separar, señalar una filiación e incluso una diferencia con el propio contenido de la obra.

El diario inédito... se encuentra en una hibridación de géneros y formas (diarios, Tractatus, poema en prosa, entrevistas), que se expresan desde los primeros encuentros del lector con la obra, incluso con los marcos referenciales propuestos por el autor y por los otros autores, en el caso de la cuarta de forros. A pesar de ello, los marcos referenciales de la obra pueden ser cuestionados en cuanto a la filiación o rechazo de un género literario e incluso en el contenido del libro, puesto que al leerlo no se trata de un diario tradicional; hay aforismos (como se menciona en la cuarta de foros), pero también reflexiones lingüísticas, fragmentos biográficos y autobiográficos, proposiciones que no aportan algo al desarrollo del pensamiento en el texto; incluso el contenido no revela esa "tragedia del hombre actual" que señala Yezzed en el prólogo.

Más allá de las obras citadas explícitamente, tal parecería que El diario inédito... consiste en un número determinado de referencias, lo cual ubica al autor como aquello que le da unidad a la obra, además de ser el "rescatador de voces" de los otros autores en el diálogo que existe entre su obra y las demás; por su lado, el lector, con otro tanto sinfín de citas más, es quien tratará de unir los tantos pedazos de la obra.

En este sentido, obras como El diario inédito... invitan a una participación activa del lector, cuestionando los marcos propuestos 
para la interpretación, la cual puede cambiar si se dejan de lado esos marcos referenciales, partiendo incluso desde el título del libro. En este sentido, las características de esta obra (hibridación de géneros literarios, la indeterminación temporal y espacial -en donde se puede añadir cierta incoherencia histórica-, la transtextualidad u apropiación de otros textos; además de la descanonización en los diarios literarios) invitan a una participación activa del lector, ya sea haciéndolo cómplice de quien enuncia o bien implicándolo en la obra para que desentrañe el argumento de la misma. Esto se puede apreciar desde que se lee el prólogo a El diario inédito..., pues ahí se habla de un Wittgenstein inventado o, más bien, apropiado; además, se invita a establecer la relación entre el Tractatus y este diario literario, pero también a perseguir los nexos entre este último y las otras fuentes de las que bebe.

\section{Bibliografía}

Ardila, Omar, 2014, El diario inédito del filósofo vienés Ludwig Wittgenstein, mayo. Disponible en: http://omarardila.blogspot. $\mathrm{mx} / 2014 / 05 /$ el-diario-inedito-del-filosofo-vienes.html (Consultado: 4/V/2018).

Ballart, Pere, 2005, El contorno del poema: claves para la lectura de la poesía, Acantilado, Barcelona.

Consuegra, Jorge, 2011, Fredy Yezzed, marzo. Disponible en: http://www.librosyletras.com/2011/03/freddy-yezzed.html (Consultado: 5/X/2017).

Fischer-Lichte, Erika, 2007, “El Posmoderno: ¿continuación o fin del Moderno? La literatura entre la crisis cultural y el cambio cultural", en El Postmoderno, el postmodernismo y su critica, Desiderio Navarro (sel.), Desiderio Navarro y Esther Pérez (trad.), Margarita Mateo Palmer (pról.), Criterios, La Habana, pp. $154-167$. 
Genette, Gerard, 1989, Palimpsestos: la literatura en segundo grado, Celia Fernández Prieto (trad.), Taurus, Madrid.

Hassan, Ihab, 2007, "El pluralismo en una perspectiva posmoderna”, en El Postmoderno, el postmodernismo y su critica, Desiderio Navarro (sel.), Desiderio Navarro y Esther Pérez (trad.), Margarita Mateo Palmer (pról.), Criterios, La Habana, pp. 19-42.

Hierro, Manuel, 1999, "La comunicación callada de la literatura. Reflexión teórica sobre el diario íntimo", Mediatika: cuadernos de medios de comunicación, núm. 7, Donostia, pp. 103-127.

Iser, Wolfgang, 2015, "El proceso de lectura: enfoque fenomenológico", Estética de la recepción, José A. Mayoral (comp.), José A. Mayoral (nota preliminar), Arnold Rothe (intro.), Arco, Madrid, pp. 215-244.

Luján Atienza, Ángel Luis, 2000, Cómo se comenta un poema, Síntesis, Madrid.

Marinkovich, Juana, 1999, "El análisis del discurso y la intertextualidad", Boletín de Filología de la Universidad de Chile, vol. 37, núm. 2, Valparaíso, 1998-1999, pp. 729-742.

Picard, Hans Rudolf, 1981, "El diario como género entre lo íntimo y lo público", Anuario de la Sociedad Española de Literatura General y Comparada, núm. 4, Madrid, pp. 115-122.

Pérez Chico, David, 2011, "Los Diarios secretos de Ludwig Wittgenstein. Una lectura perfeccionista", en El diario como forma de escritura y pensamiento en el mundo contemporáneo, Luisa Paz Rodríguez Suárez y D. Pérez Chico (eds.), Institución Fernando el Católico/Universidad de Zaragoza, Zaragoza, pp. 71-94.

Wittgenstein, Ludwig, 2016, Tractatus lógico-philosophicus, Alianza Editorial, Madrid.

Yezzed, Fredy, 2016, El diario inédito del filósofo vienés Ludwig Wittgenstein, Ediciones del Dock, Colección 46 de Pez Náufrago, Buenos Aires. 
,2011, "Selección poética", Revista Círculo de poesía, enero. Disponible en: https://circulodepoesia.com/2011/01/foja-depoesia-no-271-fredy-yezzed/ (Consultado: 8/V/2017). 